\title{
Shigella dysenteriae
}

National Cancer Institute

\section{Source}

National Cancer Institute. Shigella dysenteriae. NCI Thesaurus. Code C86745.

A species of facultatively anaerobic, Gram negative, rod shaped bacteria in the phylum Proteobacteria. This species is non motile, indole negative, cannot ferment lactose and produces Shiga toxin. S. dysenteriae is a pathogen that causes severe forms of shigellosis in primates. 